\title{
Ensayos para la extracción de ADN y estandarización de RAPDs en Moniliophthora roreri
}

\author{
Assays for DNA extraction and standardization of RAPD in Moniliophthora roreri
}

\section{Testes de extração de DNA e padronização de RAPDs em Moniliophthora roreri}

\author{
Luis Enrique Quintero Nuñez ${ }^{1}$, Liliana Yanet Suárez Contreras², Giovanni Chaves Bedoya ${ }^{3}$
}

Forma de citar: L.E. Quintero-Nuñez, L.Y. Suárez-Contreras, G. Chaves-Bedoya "Ensayos para la extracción de ADN y estandarización de RAPDs en Moniliophthora roreri”, Respuestas, vol. 22, no. 2, pp. 48-58, 2017.

Recibido:

Enero 13 de 2017

Aceptado:

Mayo 24 de 2017

\section{Resumen}

Antecedentes: Moniliophthora roreri es el agente causal de la moniliasis del cacao, enfermedad limitante que presentan las regiones productoras de cacao (Theobroma cacao L.), siendo el principal problema fitosanitario para Colombia. Conocer el comportamiento de $M$. roreri In vitro, es importante para su estudio. Además, continuar con los trabajos que definan la estructura genética de las poblaciones del fitopatógeno es interesante pues refleja su historia evolutiva y su potencial para evolucionar. Objetivo: Observar el crecimiento y desarrollo de 11 aislamientos de $M$. roreri obtenidos de 6 municipios de Norte de Santander: El Zulia, Cúcuta, Sardinata, El Tarra, Agua Clara, Tibú, para estandarizar ADN polimórfico Amplificado al Azar. Métodos: Se probaron cinco métodos de incubación para el aislamiento del fitopatógeno en PDB, el método donde el hongo permaneció en agitación 1 día a $120 \mathrm{rpm}$ con periodos luz/oscuridad de $12 \mathrm{~h} / 1 \mathrm{Universidad}$ Francisco de Paula Santander $2 \mathrm{~h}$ a temperatura de 25 a $28^{\circ} \mathrm{C}$, e incubación a $28^{\circ} \mathrm{C}$ en completa oscuridad; mostró mejores resultados, al observar crecimiento del micelio de M. roreri durante 8 días razón por la cual se continuó con la extracción del ADN de los aislamientos, y se estandarizó la técnica RAPD (ADN Polimórfico Amplificado al Azar). Resultados: La incubación a $28^{\circ} \mathrm{C}$ en completa oscuridad, mostró mejores resultados en cuanto al crecimiento del hongo y se logró estandarizar los RAPDs con el Oligo 4, Oligo 8, Oligo10 y OPA 10. En la PCR, con una temperatura de desnaturalización de $94^{\circ} \mathrm{C}$ por cinco minutos, 35 ciclos a $94^{\circ} \mathrm{C}$ por 30 segundos, temperatura de alineamiento de $36^{\circ} \mathrm{C}$ (para el Oligo 8 y 10 ) y $32^{\circ} \mathrm{C}$ (para el Oligo 4 y OPA 10 ) por un minuto, $72^{\circ} \mathrm{C}$ por 2 minutos y un ciclo final de $72^{\circ} \mathrm{C}$ por 7 minutos. Conclusión: se logró determinar la temperatura de incubación de $28^{\circ} \mathrm{C}$ en oscuridad y estandarizar la técnica RAPDs para Moniliophthora roreri.

Palabras claves: ADN, cacao, marcador molecular, patógeno de cacao.

${ }^{3}$ Doctorado en Biotecnologia Vegetal

gchavesb@ufps.edu.co orcid.org/0000-0002-2320-6824 Universidad Francisco de Paula Santander Cúcuta - Colombia 
of phytopathogen populations is interesting because it reflects their evolutionary history and their potential for evolution. Objective: To observe the growth and development of 11 isolates of M. roreri obtained from 6 municipalities of Norte de Santander: El Zulia, Cúcuta, Sardinata, El Tarra, Agua Clara, Tibú, to standardize Random Amplified polymorphic DNA. Methods: Five incubation methods were tested for phytopathogen isolation in PDB, the method where the fungus remained agitated for 1 day at $120 \mathrm{rpm}$ with light / dark periods of $12 \mathrm{~h} / 12 \mathrm{~h}$ at 25 to $28^{\circ} \mathrm{C}$, and incubation at $28^{\circ} \mathrm{C}$ in complete darkness; Showed better results, when observing growth of $M$. roreri mycelium during 8 days reason for which the extraction of DNA from the isolates was continued, and RAPD (Random Amplified Polymorphic DNA) technique was standardized. Results: Incubation at $28^{\circ} \mathrm{C}$ in complete darkness showed better results in fungus growth and RAPDs were standardized with Oligo 4, Oligo 8, Oligo 10 and OPA 10. In the PCR, with a denaturation temperature of $94^{\circ} \mathrm{C}$ for five minutes, 35 cycles at $94^{\circ} \mathrm{C}$ for 30 seconds, alignment temperature of $36^{\circ} \mathrm{C}$ (for Oligo 8 and 10) and $32^{\circ} \mathrm{C}$ (for Oligo 4 and OPA 10) for one minute, $72^{\circ} \mathrm{C}$ for 2 minutes and a final cycle of $72^{\circ} \mathrm{C}$ for 7 minutes. Conclusion: it was possible to determine the incubation temperature of $28^{\circ} \mathrm{C}$ in the dark and to standardize the RAPDs technique for Moniliophthora roreri.

Key words: DNA, cocoa, molecular marker, cocoa pathogen.

\section{Resumo}

Antecedentes: Moniliophthora roreri é o agente causal da monilíase do cacau, uma doença limitante apresentada pelas regiões produtoras de cacau (Theobroma cacao L.), sendo o principal problema fitossanitário para a Colômbia. Conhecendo o comportamento de M. roreri In vitro, é importante para o seu estudo. Além disso, prosseguir o trabalho que define a estrutura genética das populações de fitopatógenos é interessante porque reflete sua história evolutiva e seu potencial para evoluir. Objetivo: Observar o crescimento e o desenvolvimento de 11 isolados de $M$. roreri obtidos de 6 municípios do Norte de Santander: El Zulia, Cúcuta, Sardinata, El Tarra, Agua Clara, Tibú, para padronizar o DNA polimórfico Amplificado Aleatório. Métodos: foram testados cinco métodos de incubação para o isolamento do fitopatogênio no PDB, método em que o fungo permaneceu agitado durante 1 dia a $120 \mathrm{rpm}$ com períodos claros / escuros de $12 \mathrm{~h} / 1$ Universidade Francisco de Paula Santander $2 \mathrm{~h}$ a uma temperatura de 25 a 28 ${ }^{\circ} \mathrm{C}$, e incubação a $28^{\circ} \mathrm{C}$ em completa escuridão; apresentaram melhores resultados, observando o crescimento do micelio de $M$. roreri durante 8 dias, razão pela qual a extração do DNA dos isolados foi continuada, e a técnica RAPD (Random Amplified Polymorphic DNA) foi padronizada. Resultados: a incubação a $28^{\circ} \mathrm{C}$ em completa escuridão apresentou melhores resultados no crescimento de fungos e os RAPDs foram padronizados com Oligo 4, Oligo 8, Oligo 10 e OPA 10. No PCR, com uma temperatura de desnaturação de $94^{\circ} \mathrm{C}$ durante cinco minutos, 35 ciclos a $94^{\circ} \mathrm{C}$ durante 30 segundos, temperatura de alinhamento de $36^{\circ} \mathrm{C}$ (para Oligo 8 e 10) e $32^{\circ} \mathrm{C}$ (para Oligo 4 e OPA 10) durante um minuto, $72{ }^{\circ} \mathrm{C}$ durante 2 minutos e um ciclo final de $72{ }^{\circ} \mathrm{C}$ durante 7 minutos. Conclusão: foi possível determinar a temperatura de incubação de $28^{\circ} \mathrm{C}$ no escuro e padronizar a técnica de RAPD para Moniliophthora roreri.

Palavras-chave: DNA, cacau, marcador molecular, patógeno do cacau.
Julio - Dic. 2017

ISSN 0122-820X

E-ISSN 2422-5053

PP: $48-58$ 
No. 2

\section{Introducción}

La especie vegetal cacao, ha sido denominada en términos científicos (Theobroma cacao L.) por el botánico Lineo quien la clasificó [1]. Esta planta es originaria de la franja del trópico de América, su origen fue en los nacimientos de los ríos Amazonas y Orinoco. El cultivo se produce óptimamente en zonas agroecológicas presentes entre los 400-1200 m.s.n.m., a una temperatura de 23 a $28^{\circ} \mathrm{C}$ y una humedad relativa de $70-80 \%$, planta que es afectada por la moniliasis del cacao, causada por el hongo Moniliophthora roreri (CIF.) H.C. E vans que infecta frutos jóvenes y de otras especies afines destruyendo así la semilla que es el producto comercial. Su rápida diseminación y los daños que ha causado en once países tropicales han incrementado la preocupación por otros continentes [1].

En Colombia esta enfermedad causa pérdidas cercanas al $50 \%$ de la cosecha anual que es de aproximadamente 50.000 toneladas, cuyo valor supera los $\$ 200.000$ millones [2]. Dada la importancia socioeconómica para Norte de Santander, ha tenido un marcado interés por el desarrollo tecnológico en lo referente a variedades, semillas, manejo integrado de plagas y enfermedades, ya que se presentan problemas importantes en el cultivo de cacao como: baja producción por problemas fitosanitarios, escasez de masa crítica, baja mano de obra, baja adopción y transferencia de tecnología [2], [3], [4].

El cultivo de cacao en Norte de Santander produce al año 4.500 ton en las 12.000 has sembradas, principalmente en los municipios de Tibú, El Zulia, Cúcuta, El Tarra, Teorema, Sardinata, Bucarasica, Cachira, La Esperanza y Ocaña [5]. De ahí la importancia de los municipios tomados como población para realizar la investigación, donde se aislaron las muestras. Con el fin de asegurar el amparo de las inversiones que se están haciendo, se deben iniciar con carácter urgente las investigaciones que conduzcan al control de una enfermedad tan grave y sobre la cual es poco lo que se conoce. También la identificación de especies a nivel molecular permite caracterizar variedades y polimorfismos a nivel genético para facilitar la comparación y la relación benéfica que estas puedan traer.

Los objetivos de la investigación fueron aislar el hongo Moniliophthora roreri, de seis municipios del departamento de Norte de Santander y estandarizar la técnica molecular RAPDs, para continuar con los estudios de caracterización molecular del fitopatógeno.

\section{Materiales y Métodos}

\subsection{Obtención y conservación de aislamientos de $M$. roreri en Caldo Papa Dextrosa (PDB)}

Los aislamientos de este estudio provienen de la investigación realizada por Suárez y Rangel [1]. El origen de las muestras es de cinco municipios de Norte de Santander así: Cúcuta (HFC001, HFC002, HFC003 y HFAC001), Sardinata (HFS001, HFS002, HFS003 y HFS008), El Tarra (HFTA001, HFTA002, HFTA003 y HFTA004), Tibú (HFT001, HFT002 y HFT003) y El Zulia (HFZ001, HFZ002 y HFZ003); las cepas madres se encontraban conservadas en agar PDA (MERCK) y se purificaron mediante repiques sucesivos en igual medio de cultivo, $\mathrm{pH} 5.6$ a $28{ }^{\circ} \mathrm{C}$ hasta obtener cepas puras del fitopatógeno; después se realizó traspaso de los aislados en medio PDB (MERCK) a Erlenmeyer con caldo papa dextrosa (PDB) [7].

Para la incubación se tuvieron en cuenta cinco métodos (Tabla I), variando condiciones como agitación, fotoperiodo (luz/oscuridad) $\mathrm{y}$ temperatura.

Una vez aisladas las colonias del fitopatógeno fueron conservadas mediante dos métodos diferentes; el primero, en círculos de papel 
filtro colonizados con el hongo y almacenados en microtubos a $4^{\circ} \mathrm{C}$ y el segundo, en viales con solución salina estéril al $0.85 \%$ de $\mathrm{NaCl}$, refrigerados a $4^{\circ} \mathrm{C}$ para estudios posteriores.

Tabla I. Método de incubación y sus variables

\begin{tabular}{|c|c|c|c|}
\hline VARIABLE & $\begin{array}{l}\text { AGITACIÓN } \\
\text { (RPM)/DÍAS }\end{array}$ & $\begin{array}{l}\text { FOTOPERIODO } \\
\text { LUZ/OSCURIDAD }\end{array}$ & $\begin{array}{l}\text { TEMPERATURA } \\
\left({ }^{\circ} \mathrm{C}\right)\end{array}$ \\
\hline 1 & Sin agitación & $12 \mathrm{~h} / 12 \mathrm{~h}$ & Ambiente 25 a $28^{\circ} \mathrm{C}$ \\
\hline 2 & $\begin{array}{l}150 / 2 \\
\text { Después incubación }\end{array}$ & $\begin{array}{l}12 \mathrm{~h} / 12 \mathrm{~h} \\
24 \mathrm{~h} \text { oscuridad }\end{array}$ & $\begin{array}{l}\text { Ambiente } 25 \text { a } 28^{\circ} \mathrm{C} \\
28^{\circ} \mathrm{C}\end{array}$ \\
\hline 3 & Sin agitación & $24 \mathrm{~h}$ oscuridad & Incubación a $28^{\circ} \mathrm{C}$ \\
\hline 4 & $\begin{array}{l}120 / 3 \\
\text { Después incubación }\end{array}$ & $\begin{array}{l}24 \mathrm{~h} \text { oscuridad } \\
24 \mathrm{~h} \text { oscuridad }\end{array}$ & \multirow{2}{*}{$\begin{array}{l}\text { Ambiente } 25 \text { a } 28^{\circ} \mathrm{C} \\
28^{\circ} \mathrm{C}\end{array}$} \\
\hline 5 & $\begin{array}{l}120 / 1 \\
\text { Después incubación }\end{array}$ & $\begin{array}{l}12 \mathrm{~h} / 12 \mathrm{~h} \\
24 \mathrm{~h} \text { oscuridad }\end{array}$ & \\
\hline
\end{tabular}

2.2 Extracción y visualización del ADN. Se utilizó el protocolo de extracción de ADN. Con el uso del método fenol cloroformo. La calidad de ADN se determinó por electroforesis en geles de agarosa, con Bromuro de etidio propuesto por Suárez en 2005 [6].

\subsection{Estandarización de la Téenica} Molecular, RAPD (ADN polimórfico Amplificado al Azar / Random amplified polymorphic DNA). ). Se llevó a cabo por el protocolo propuesto por Grisales y Afanador en el 2007 [7]; se utilizaron los cebadores que según los autores presentaron más polimorfismo (Tabla II). Los productos de amplificación, y el marcador de $1 \mathrm{~kb}$, fueron corridos en geles de agarosa al 1,5\% en una cámara de electroforesis horizontal a 100 voltios por 100 minutos, visualizados en un transiluminador de luz UV.

Tabla II. Cebador para RAPD.

\begin{tabular}{|l|l|l|}
\hline CEBADOR* & SECUENCIAS & REFERENCIA \\
\hline Oligo 4 & $5^{\prime}$ - AAA GCT GCG G-3' & Grisales y Afanador \\
\hline Oligo 8 & $5^{\prime}$ - GTG ACG CCG C-3' & Grisales y Afanador \\
\hline Oligo 10 & $5^{\prime}$ - GGG GGC CTC A-3' & Grisales y Afanador \\
\hline OPA 10 & $5^{\prime}$ - GTG ATC GCA G-3' & Grisales y Afanador \\
\hline
\end{tabular}

*Los cebadores u oligonucleótidos son producidos por International DNA Technologies (IDT). Fuente: Autor

\section{Resultados y análisis}

\subsection{Obtención de los aislamientos $M$. roreri en Caldo Papa Dextrosa (PDB).}

Se realizaron los repiques de los aislamientos madres en el medio de cultivo PDA y se evidenció que presentan un crecimiento lento permitiendo que otros microorganismos contaminantes del medio ambiente limiten su normal desarrollo, por esta razón se hicieron repiques sucesivos hasta obtener la cepa pura. Se lograron recuperar once aislamientos de seis municipios de Norte de Santander (Tabla III).

Tabla III. Aislamientos de Moniliophthora roreri de los seis municipios de Norte de Santander

\begin{tabular}{|l|l|}
\hline MUNICIPIO & CODIGO \\
\hline Cúcuta & HFC001, HFC002 \\
\hline Agua clara & HFAc001 \\
\hline Sardinata & HFS003, HFS008 \\
\hline El Tarra & HFTA002, HFTA003 \\
\hline Tibu & HFTI001, HFTI002 \\
\hline El Zulia & HFZ001, HFZ002 \\
\hline
\end{tabular}


Vol. 22

No. 2

Julio - Dic. 2017

ISSN 0122-820X

E-ISSN 2422-5053

PP: $48-58$

Dentro de los análisis realizados por Phillips [8], encontró que algunos aislados presentan la capacidad de crecer y esporular menos que otros, posiblemente como un mecanismo de economía metabólica baja, debido a las condiciones favorables de crecimiento (Figura 1).

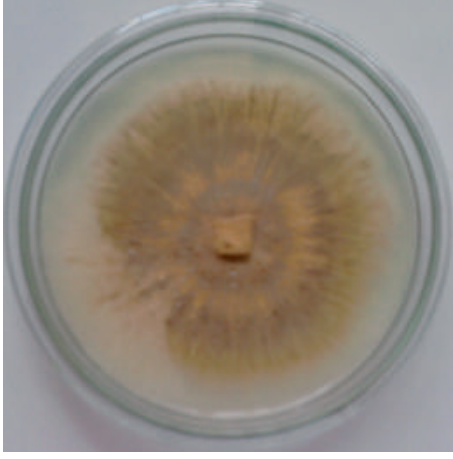

A

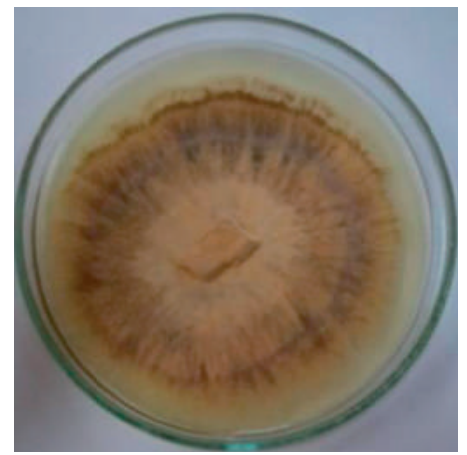

B

Figuras 1. Cepas M. roreri. A) HFTA002; B) HFZ001 Fuente: Autor

Teniendo en cuenta lo propuesto por Suárez en 2005[6]. Y Villavicencio [9], quien describe que las muestras de $M$. roreri se cultivan en medios específicos sólidos (V8MAA: Jugo V8-Maltosa-Asparagina-Agar) como en líquido (V8MA+PDB), se debe mantener el medio específico para que el hongo se desarrolle. Al realizar los primeros repiques de los aislamientos en medio líquido no se obtuvieron resultados positivos, se analizaron las condiciones dadas y se pudo inferir que posiblemente no se debía a la ausencia de nutrientes que necesita el microorganismo para desarrollarse sino a las condiciones medio ambientales y a la contaminación exógena, por tal razón se varió el método de incubación. (Tabla I).
Inicialmente se aplicaron tres métodos de incubación para los aislamientos sembrados en PDB. El método de incubación uno, se ensayó con 30 muestras por duplicado, donde se presenció turbidez en el medio a partir de los días 3 al 5 y se dejó en crecimiento hasta el día 30 , pero se observó que no hubo crecimiento del micelio (Figura 2A). Con el método de incubación dos, el ensayo se realizó para 40 muestras por duplicado, se observó turbidez, pero no el crecimiento correspondiente a $M$. roreri, la turbidez se apreció a partir de los días 1 al 3 y en el día 30 no hubo formación del micelio (Figura 2B). Con estos dos métodos no se logró el crecimiento de M. roreri.

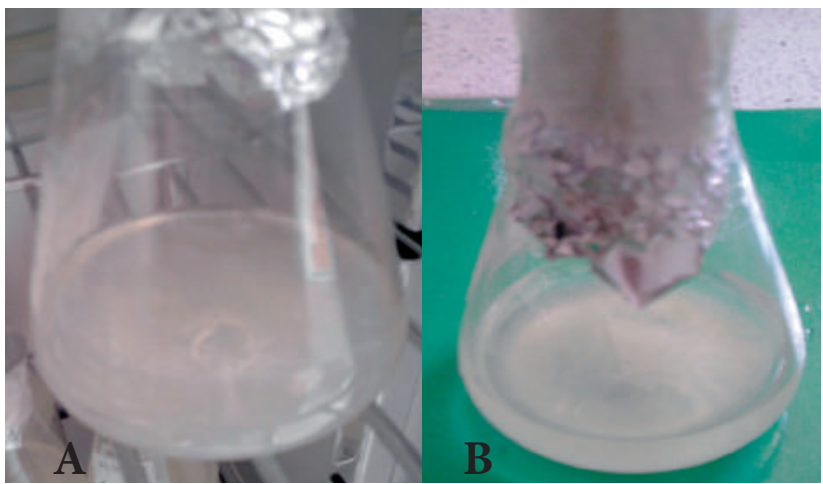

Figura 2. A) Método de incubación (1). B) Método de incubación (2). Fuente: Autor 
Para el método de incubación tres se tuvo en cuenta lo propuesto por Evans et al. [10], donde indica que el crecimiento del hongo en Caldo Papa Dextrosa (PDB) se debe dar en un cuarto oscuro a $25^{\circ} \mathrm{C}$. Por lo tanto, se modificó la temperatura a $28^{\circ} \mathrm{C}$, y se observó que este método de incubación fue favorable para el crecimiento de $M$. roreri; se ensayó con 30 muestras por duplicado, donde se presenció un medio traslucido y formación de una película a partir del tercer día y se obtuvo crecimiento de micelio en 15 muestras: HFC001(x2), HFC002, HFS003(x2), HFS008(x2),
HFTA002(x2), HFTA003, HFTI001(x2), HFTI002 y HFZ001(x2); el crecimiento de micelio abarcó la mitad del Erlenmeyer desde los 20 a 25 días y se observó el cubrimiento total del medio por el micelio después de los 30 días. Se formó el micelio en la superficie de manera consistente (Figura 3). Cada muestra presentó en su morfología una tonalidad variable, desde color café oscuro, café claro y por último color crema (Figuras 1A y 1B); también se observó que la mayoría de los aislamientos presentaron textura polvosa, $\mathrm{y}$ otros afelpada [1],[11].

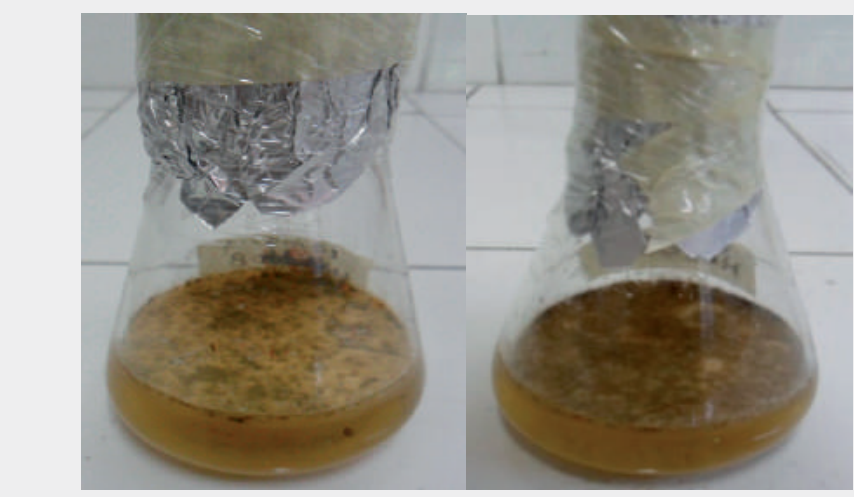

Figura 3. Incubación tres. crecimiento del micelio de $M$. roreri después de 30 días Fuente: Autor

A partir de estos aislados, se hizo la primera extracción de ADN sin obtener buenos resultados, debido a que tardó cerca de 20 días en desarrollarse; razón que permitió replantear otros dos métodos [7], uno consistió en colocar en crecimiento el aislado en una zaranda con agitación a $120 \mathrm{rpm}$ por 8 días bajo oscuridad a $26^{\circ} \mathrm{C}$. Y se observó que dejando a $M$. roreri en total oscuridad, se evidenció un crecimiento favorable del fitopatógeno.

Con el método anterior se realizó una variación de los períodos luz/oscuridad [7] y se tuvo en cuenta el método de incubación dos, en el que se había presentado más rápido turbidez en la muestra, modificando la agitación en zaranda de $150 \mathrm{rpm}$ por 2 días, con el fin de estimular la actividad del fitopatógeno y presentó mayor crecimiento.

Luego se probó la incubación cuatro, con variables de completa oscuridad, y agitación de $120 \mathrm{rpm}$ por tres días para homogenizar y estimular el crecimiento. En esta incubación, el primer ensayo se hizo con 25 muestras, y se observó el crecimiento del aislamiento HFZ001 (Figura 4). En el segundo ensayo con esta incubación, se presenció turbidez en el medio, pero no crecimiento de las otras muestras. Se observó que HFZ001 formó una película en la superficie, con una turbidez en el medio del día 1 al 3. Como solo se obtuvo esta extracción de ADN, este método no se consideró bueno para las otras muestras. 
No. 2

Julio - Dic. 2017 ISSN $0122-820 \mathrm{X}$ E-ISSN 2422-5053

\section{4}

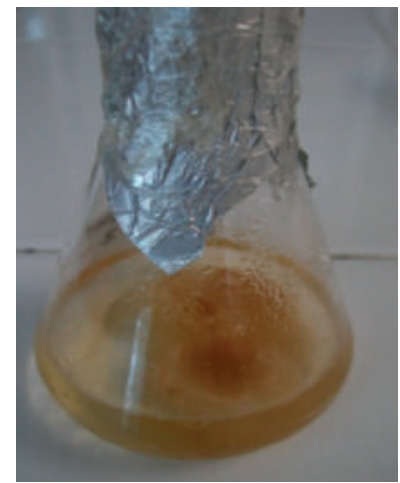

Figura 4. Incubación (4). Crecimiento del micelio de HFZ001 a los 8 días Fuente: Autor

En la incubación cinco, similar a la anterior pero con agitación por un día y con una variación de luz/oscuridad de $12 \mathrm{~h} / 12 \mathrm{~h}$, con ensayos en 45 Erlenmeyer de diferentes muestras y se obtuvo crecimiento en 15 muestras (Figura 5), de 9 aislamientos HFTA002(x2), HFTA003(x2), HFS008(x2), HFS003(x2), HFC001, HFC002, HFZ002, HFT001(x2) y HFT002(x2). Se pudo observar la formación de una película en la superficie y medio traslucido de los días 1 al 3, luego el micelio cubrió el medio del día 10 al 15 . Cada muestra presentó la morfología descrita en la incubación tres, tanto en tonalidad como textura. (Figuras 1A y 1B) [1], [11].

Se comparó la formación de micelio del método de incubación cuatro y cinco, $\mathrm{y}$ se observó que la mejor textura y consistencia fue la obtenida con el método cinco, en la que se dejó un día de agitación, incubación a $28^{\circ} \mathrm{C}$; y así se formó el micelio en la superficie a los 8 días. Con este método de incubación se obtuvieron las muestras HFZ001 y HFAC001 en PDB.

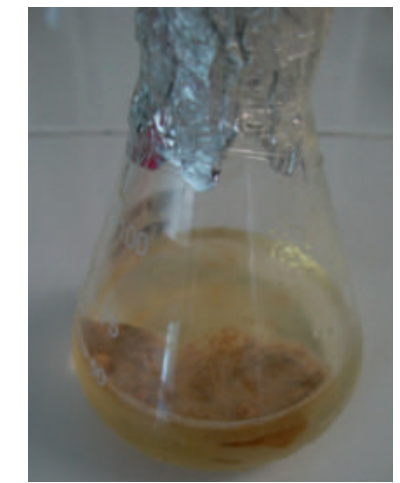

Figura 5. Incubación cinco. Crecimiento de micelio a los 8 días Fuente: Autor

\subsection{Extracción y visualización del ADN genómico de $M$. roreri.}

Un buen método de extracción de ADN, debe mantener la integridad física y bioquímica del $\mathrm{ADN}$ e incrementar sus rangos de pureza y concentración [12]. En este proyecto se realizó la extracción de ADN de 11 aislamientos de M. roreri que se obtuvieron con el método de incubación cinco, y además, se realizó la extracción de ADN de otros 9 aislamientos de $M$. roreri con la incubación tres. Se obtuvo ADN de cada extracción según Suárez [6]. Una vez corrida la electroforesis de las extracciones de $\mathrm{ADN}$, se pudo visualizar una buena cantidad y calidad de ADN de los aislamientos obtenidos de la incubación cinco (Figura 6), y así se pudo continuar los estudios moleculares del fitopatógeno $M$. roreri. Donde se aprecian claramente las bandas de ADN de las cepas HFTA002, HFTA003, HFZ001, HFZ002, HFS003, HFS008, HFC001, HFC002, HFAC001, HFT001, y HFT002, y se demuestra satisfactoriamente la extracción de ADN del fitopatógeno.

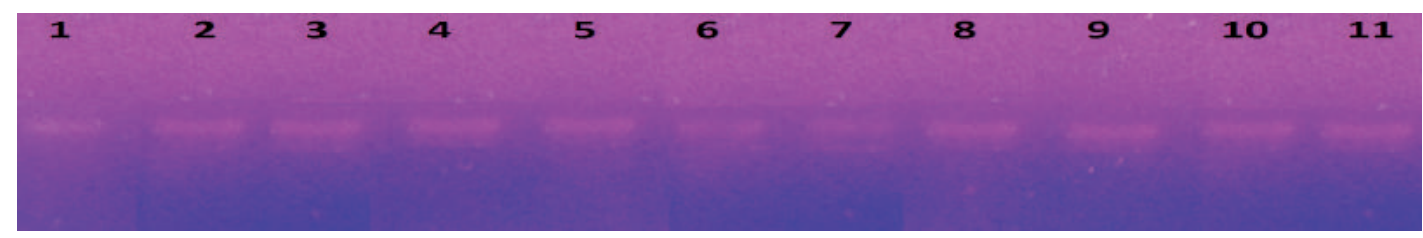

Figura 6. Electroforesis de ADN en gel de agarosa 0.7\%. muestras de M. roreri. Línea 1: HFTA002; Línea 2: HFTA003; Línea 3: HFZ001; Línea 4: HFZ002; Línea 5: HFS003; Línea 6: HFS008; Línea 7: HFC001; Línea 8: HFC002; Línea 9: HFAC001; Línea 10: HFT001; Línea 11: HFT002. 
En cuanto a la visualización de las extracciones a partir de los 9 aislamientos (HFC001, HFC002, HFS003, HFS008, HFTA002, HFTA003, HFTI001, HFTI002 y HFZ001); del método de incubación tres no se obtuvo ADN, ya que las muestras de $M$. roreri llevaban de 20 a 30 días en caldo, tiempo en el que creció y se desarrolló, al ser un cultivo viejo y no óptimo por lo que se dificulta la extracción del ADN. Según Suárez 2016 [13] para la extracción de ADN genómico se debe tener un cultivo fresco, por eso la producción del micelio debe estar entre 11 a 15 días. Además Castro, Briceño y García 2006 [14] sugieren que el tiempo de crecimiento óptimo del micelio para hacer extracciones de ADN es de 11 días, teniendo en cuenta el desarrollo del microorganismo en medio líquido.

Como no se obtuvo el ADN en estas muestras con la incubación tres, se observó el tiempo de crecimiento del hongo, para lograr la mejor extracción de ADN [6]; y se probó que la extracción óptima se realiza 8 días después de la inoculación, tiempo en el que crece el micelio del fitopatógeno sin envejecimiento; por esta razón se ensayaron los otros métodos de incubación donde se obtuvo el crecimiento del micelio más rápido. Y se consiguió un buen resultado con la incubación cinco, ya que con los otros protocolos de incubación no se consiguió la extracción del ADN.

\subsection{Estandarización de la técnica molecular, RAPD (ADN polimórfico Amplificado al Azar o Random Amplifield Polymorphic DNA).}

Con las extracciones del ADN obtenido de $M$. roreri, se probaron tres métodos para estandarizar la PCR (A, B, C). Con el método (A) propuesto por Grisales y Afanador 2007 [7] no se obtuvo amplicones. Por esta razón se hicieron dos modificaciones; el método (B) en el que se cambió la concentración y volumen en la preparación de la mezcla para la PCR como se indica en la tabla IV, con este ensayo no se consiguieron amplicones. En el método (C) se utilizó la concentración y volumen para la PCR anterior, y se modificaron las temperaturas de alineamiento para los cebadores, como lo muestra la Tabla $\mathrm{V}$, y juntando estas condiciones con el número de ciclos, se obtuvieron amplicones en la PCR con 4-6 muestras diferentes de ADN, Y se estandarizó la reacción de amplificación de los marcadores RAPD.

Tabla IV. Condiciones de Mezcla para la PCR. Método B

\begin{tabular}{|l|l|l|l|}
\hline COMPONENTES & CONCENTRACIÓN STOCK & CONCENTRACIÓN FINAL & VOLUMEN (x1) \\
\hline Agua & - & - & $33 \mu 1$ \\
\hline Buffer & $10 \mathrm{x}$ & $1 \mathrm{x}$ & $5 \mu \mathrm{l}$ \\
\hline $\mathrm{MgCl}_{2}$ & $50 \mathrm{Mm}$ & $3 \mathrm{Mm}$ & $3 \mu 1$ \\
\hline Cebador & $20 \mathrm{pmol}$ & $2 \mathrm{pmol}$ & $5 \mu 1$ \\
\hline DNTP & $25 \mathrm{Mm}$ & $0,25 \mathrm{Mm}$ & $0.5 \mu 1$ \\
\hline Taq polimerasa & $5 \mathrm{U} / \mu \mathrm{l}$ & $0.05 \mathrm{U} / \mu 1$ & $0,5 \mu 1$ \\
\hline ADN & - & - & $3 \mu 1$ \\
\hline Total & - & - & $50 \mu 1$ \\
\hline
\end{tabular}

Fuente: Autor

Con el ensayo del método (C), se obtuvo la temperatura de alineamiento para que el cebador se insertará en elADN, y se manejaron tres temperaturas con una diferencia entre ellas de $+/-2^{\circ} \mathrm{C}$. Éstas se realizaron en un termociclador con el programa térmico de amplificación de un ciclo de desnaturalización a $94^{\circ} \mathrm{C}$ por 5 minutos, seguido de 35 ciclos a $94^{\circ} \mathrm{C}$ por 30 segundos, $36^{\circ} \mathrm{C}, 34^{\circ} \mathrm{C}$ o $32^{\circ} \mathrm{C}$ por 1 minuto para alineamiento, $72^{\circ} \mathrm{C}$ por 2
Julio - Dic. 2017 ISSN 0122-820X E-ISSN 2422-5053 PP: $48-58$ 
No. 2

Julio - Dic. 2017 ISSN 0122-820X E-ISSN 2422-5053 minutos, un ciclo de extensión a $72^{\circ} \mathrm{C}$ por 7 minutos, y uno de almacenamiento a $4^{\circ} \mathrm{C}$ por tiempo indefinido.

De los dos métodos (A) y (B), se hicieron varios ensayos, con diferentes Oligos (Tabla V) y extracciones de ADN de $M$. roreri, pero no se obtuvieron amplicones (Figura 7A). Con el método (B) donde se cambiaron las concentraciones, se utilizaron unas más bajas que el método (A), teniendo en cuenta que las concentraciones resultaban fundamentales para la optimización de la reacción, sobre todo para aumentar la veracidad de la reacción de la Taq polimerasa. Como no se habían obtenido amplicones, se procedió con el método $(\mathrm{C})$, el cual difiere las temperaturas y los ciclos de la PCR. Y así se logró la amplificación de las muestras en los ensayos y la estandarización final de RAPD (Figura 7B y 7C).
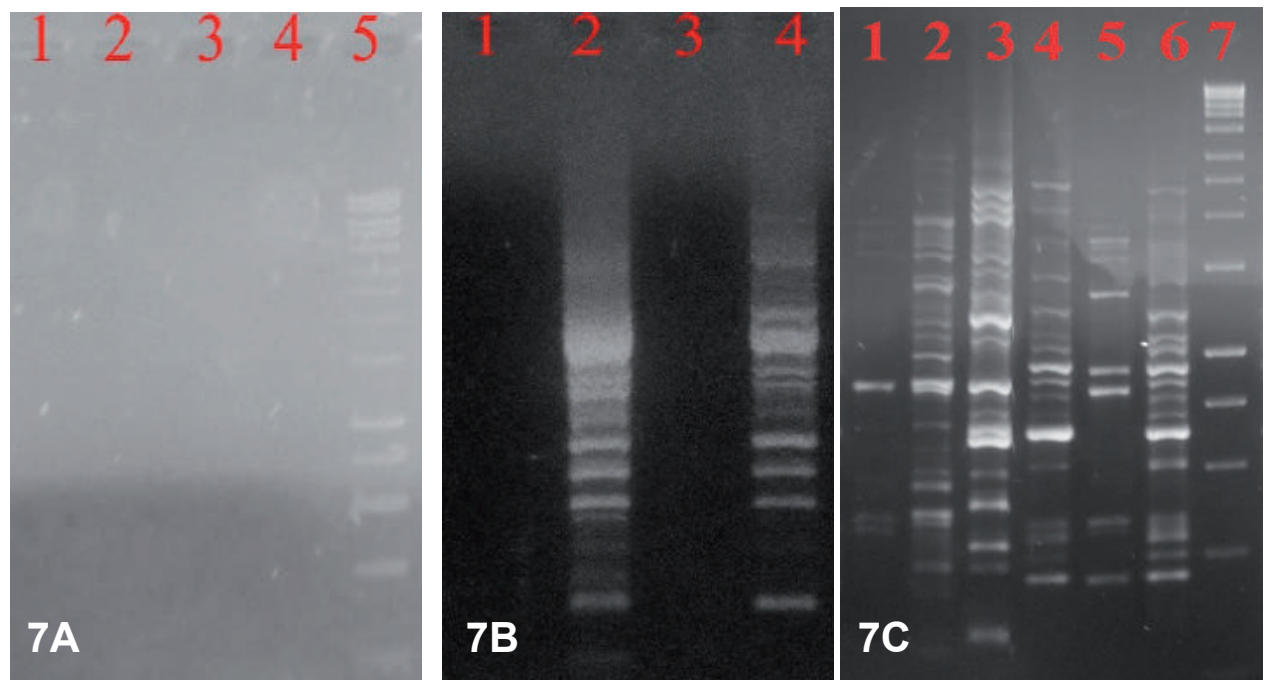

Figura 7. Electroforesis de RAPD. A) línea 1 al 4: muestras sin amplificación; línea 5: marcador 1kb. b) método (c) con el ADN del aislamiento HFC002. amplicones con el oligo 4: línea 1: temperatura de alineamiento $34^{\circ} \mathrm{C}$; línea 2 : $\mathrm{t}^{\circ}$ de $32^{\circ} \mathrm{C}$. amplicones con el opa 10: línea 3: temperatura de alineamiento $34^{\circ} \mathrm{C}$; línea $4: t^{\circ}$ de $32^{\circ} \mathrm{C}$. C) Electroforesis de RAPDs con el Oligo 4 con temperatura de alineamiento $32^{\circ} \mathrm{C}$; línea 1: HFT001, línea 2: HFC002, línea 3: HFZ001, línea 4: HFZ002, línea 5: HFS003, línea 6: HFS008, línea 7: marcador 1kb.

Fuente: Autor

En cuanto a la temperatura de alineamiento fue importante tener en cuenta que la unión del primer o cebador de manera correcta en el ADN de la muestra, además se disminuyeron los ciclos para contribuir a la confiabilidad de la reacción $T a q$ polimerasa en la extensión de los nucleótidos. Como resultado se logró estandarizar la temperatura de alineamiento para cada cebador (Tabla V). Y se probó que la temperatura de $34^{\circ} \mathrm{C}$ no generó amplicones. (Figura 7B).

Tabla V. Cebadores para RAPD con la temperatura de alineamiento

\begin{tabular}{|l|c|c|}
\hline \multicolumn{1}{|c|}{ CEBADOR } & SECUENCIA & $\begin{array}{c}\text { TEMPERATURA DE } \\
\text { ALINEAMIENTO }\end{array}$ \\
\hline Oligo 4 & 5'- AAA GCT GCG G-3' & $32^{\circ} \mathrm{C}$ \\
\hline Oligo 8 & 5'- GTG ACG CCG C-3' & $36^{\circ} \mathrm{C}$ \\
\hline Oligo 10 & 5'- GGG GGC CTC A-3' & $36^{\circ} \mathrm{C}$ \\
\hline OPA 10 & 5'- GTG ATC GCA G-3' & $32^{\circ} \mathrm{C}$ \\
\hline
\end{tabular}




\section{Conclusiones}

La estandarización de la técnica RAPDs se logra con ADN obtenido en condiciones de incubación de $28^{\circ} \mathrm{C}$ para $M$. roreri a partir de 11 cepas provenientes de los municipios de Norte de Santander. Las temperaturas ideales para alineamiento fueron de $32^{\circ} \mathrm{C}$ y $36^{\circ} \mathrm{C}$, las cuales con las modificaciones en la concentración de reactivos para la PCR, permitieron conseguir los amplicones para cada aislamiento, importantes para poder continuar con la caracterización molecularmente de $M$. roreri.

\section{Agradecimientos}

Los autores expresan su agradecimiento a la Facultad de Ciencias Básicas, que permitió la estandarización de los RAPD en su laboratorio. A la Ing. Alba Luz Rangel Riaño y al Ing. Luciano López, por su apoyo en el laboratorio de Biología Molecular. Al Fondo de Investigaciones de la Universidad Francisco de Paula Santander quien financió el proyecto. Y a FEDECACAO, quien facilitó las mazorcas de cacao para la toma de muestras de Monilia de los diferentes municipios de Norte de Santander.

\section{Referencias}

[1] L. Suárez y A. Rangel. "Aislamiento de microorganismos para control biológico Moniliophthora roreri. Acta Agronómica". 62 (4):370-378. 2013

[2] C. Ramírez, Federación Nacional de Cacaoteros. Campaña contra la monilia. Ministerio de Agricultura y Desarrollo rural. Colombia. 2008.

[3] L. Y. Suarez Contreras, "Aislamiento e identificación de Moniliophthora roreri causante de la moniliasis en municipios del nororiente Colombiano", Respuestas, vol. 11, no. 1, pp. 3-8, 2006.
[4] L. Y. Suarez y C. P. Cabrales, "Identificación de especies de cepas nativas de Trichoderma sp., Bacillus sp y evaluación de su potencial antagonista in vitro frente al hongo fitopatógeno nativo Moniliophthora roreri en el departamento de Norte de Santander", Respuestas, vol. 13, no. 1, pp. 45-56, 2008.

[5] FEDECACAO (Federacion Nacional de Cacaoteros). 2011. Estadísticas acerca de la población nacional registrada de cacao en grano. Bogotá. Disponible en: http://www.fedecacao.com.co/ site/index.php/1eco-economia/2econacionales. Consultado 11/15/2012.

[6] L. Y. Suarez Contreras, "Extracción y purificación delADN de Moniliophthora roreri hongo que ataca el cacao en Norte de Santander". Respuestas, vol. 10, no. 2, pp. 3-7, 2005.

[7] Grisales, S. y Afanador, L. 2007. Análisis de variabilidad genética en Moniliophthora roreri con AP-PCR y RAPD en Antioquia, Colombia. Rev. Col. Biotecnol. 9(2):15-32. Mcdonald, Bruce. The Population Genetics of Fungi: Tool and Techniques. Symposium Population Genetics of Soilborne Fungal Plant Pathogens. Phypathology 87 (4): 448-452. 1997.

[8] Phillips, M. W. Origin, biogeography, genetic diversity and taxonomic affinities of the cacao (Theobroma cacao) fungus Moniliophthora roreri (Cif.) Evans et ál, as determined using molecular, phytopathological and morphophysiological evidence. Thesis for the degree of Doctor of Philosophy. Department of Agricultural Botany, School of Plant Sciences. The University of Reading. RG6 6AS, UK. 2003
Julio - Dic. 2017

ISSN 0122-820X

E-ISSN 2422-5053

PP: 48-58 
[9] Villavicencio, M.Caracterización morfológica, fisiológica y patogénica de Moniliophthora roreri aislados de cinco provincias de la CostaEcuatoriana. Tesis de grado. Escuela Superior Politécnica del Litoral. Guayaquil, Ecuador. 2010.

[10] Evans, H. C, Holmes, K. A. y Reid, A. P. Phylogeny of the frosty pod pathogen of cocoa. Plant Pathology, 52(4): 476485. 2003.

[11] González, A y Roble, A. Aislamiento y caracterización del hongo Moniliophthora roreri (monilia) en frutos de Theobroma cacao 1. (cacao) del cultivar San José del real de la carrera, Usulután. Tesis de grado. Universidad de El Salvador. San Salvador, El Salvador, Centroamerica, p 64-65. 2014.

[12] Sambrok, J. Y Rusell, D. Molecular cloning, 3rd ed. Cold Spring Harbor laboratory, New York. 2001.

[13] Suárez, L. Identificación molecular de aislamientos de Moniliophthora roreri en huertos de cacao de Norte de Santander, Colombia. Acta Agronómica. 65 (1) p 44-50. 2016.

[14] Castro, Y., Briceño, A., García, M. E. Mycosphaerella fijiensis y musícola: Comportamiento en medio líquido V-8 (Mycosphaerella fijiensis and musicola: Performance in liquid V-8 medium). Tesis de grado. Universidad de los Andes. Facultad de Ciencias. Centro de Ingeniería Genética-CIGEN - Mérida. Venezuela. 2006. 